\title{
UNDERGRADUATE LANGUAGE PROBLEMS IN SHORT STORY THROUGH CREATIVE INTERPRETATION
}

\author{
Ms.Manal Ben- Ahmeid \\ Mr.farhan Ali \\ Misurata University
}

\begin{abstract}
:
This paper is conducted to shed the light on English language problems Libyan undergraduate students face in short story through creative interpretation in reading and writing. Creative writing is a wide range of literature and it deals not only with language but also with the wide imagination of writers. However, it is well known that if language problems increase, then even the imagination cannot help because writing techniques and creativity go on the same path. It has always been a great help for the writers to organize and deliver their writing in a suitable form. Most Libyan students cannot, they have many problems in composing, therefore; when they are asked to conduct a creative writing task, they find it enormously difficult and challenging. Those who have the ability to produce are the talented and skillful ones. In this paper, the aim is to encourage and motivate Libyan students to be effected to creative reading and writing as well as grow their skills and talents. Furthermore, this paper will deal with language problems in reading and writing that are mostly common in all levels of learners, and it will focus mostly on the scope of short story. In addition, the purpose of this paper is to provide ideas, suggestions, and solutions according to the problems that are encountered throughout this study. Reading this paper, will help Libyan
\end{abstract}


EFL teachers realize that creative writing is a talent or a skill that has to be practiced; therefore, we will provide ideas to help teachers avoid favoring students who have the talents and skills in reading and writing over others by treating them equally, helping them grow their ability in being creative. There are some important elements that will be discussed throughout this study and the most elements of all is for Libyan EFL teachers and students to understand that there is a significant relationship between what the learner writes and what he/she reads which is called creative reading. In this paper we will present how the reading skill is also neglected by Libyan students. Students do not read for interest unless they are forced to do so for different reasons. Reading skill is not practiced by Libyan students even in their first language. Unfortunately, Libya is a culture that does not encourage, support, facilitate and provide for reading. Therefore, in this paper, the aim is also to help Libyan students learn that reading someone's piece of work is an essential step for developing the skill of creative writing and that provides the history or background about the expected text, even an imagination for an inspired story. Furthermore, providing this paper is to help Libyan students believe that the more the learner reads, the more he/she writes and creates. We would like students to believe that inspiration and imagination are the path for a readable and meaningful story which leads the writer to creativity. And, we believe that if EFL teachers find a way to provide creativity, students will gain the knowledge needed to write and read creatively.

\section{Introduction:}

The statement that " Literature is considered to be one of the most difficult subjects to teach and the one that is very variable in forms, 
poetry, short story, novel and so on." (Mullik, 1980, p.3), implies that the idea in literature is not just to teach the learner, but to lead him/her get in depth.Even though Libyan EFL teachers try their best to transmit the knowledge in the best way possible, some Libyan students are not aware of the fact that critical reading of a certain text is one of the most effective procedures for analyzing critics arguments, to figure out what makes them existing and variable. It is worth mentioning that most of the Libyan students are not completely aware of the way language is used when it comes to creative writing especially in the scope of short story. To be specific, the current study will concentrate on short story, which is considered to be the most common form of literature, and in this case of creative writing and reading, as well as the elements that may contribute in the process of writing, and how reading plays an important role in being creative in composing a short story. According to Morley (2007) short story is of a great value as you write, you learn. "You learn by writing short stories. Keep writing short stories. The money is in novels, but writing short stories keeps your writing lean and pointed" ( p.13). Creative writing is not just a piece of writing but it contains a wide imagination enriched with emotions, fiction, experience and the ability to transmit your message in a much advanced and refreshing style ( Morley, 2007).

Stinger (2002) points out that, literary centers where young writers apprenticed themselves to master creative writing in cafes and pubs, the United States of America, because of its geographical expanse, has developed colleges and universities as gathering places for writing talent to be encouraged.It would be, technically speaking, unfair to cover every aspect of creative writing, as it would be almost impossible to give each 
genre its deserving value in this short paper, so, to avoid that issue and to focus only on one type of creative writing, short story has been chosen which is without doubt one of the most common type of literature. However, in Libya there is no concentration on literacy in general and growing the abilityof students mastering creative writing and reading in the scope of short story, it is a skill that we just practice and learn in classrooms at schools and universities. The approach to good short story writing is an interaction within a prior greatness or experience. For instance, to write a ghost story, there are certain rules and forms as well as the environment itself may help. Mcgurl (1998) says "Write at night. Dim the lights in your writing room, put the curtains open, so that anyone or anything could be looking at you. Write late, when everyone else has gone to bed. Write after drinking a cup of coffee or tea to free your imagination, write scared". (p. 159) Write outdoors in a nice site seeing, write when you're sad, write comfortable. In other words, if the Libyan government provides and exposes students to the right reading and writingenvironment, such as gatherings in centers, cafes, clubs, institutions, workshops and schools, as well as shown students how it is done. Then, Libyan students could master the ability to read and write creatively and compose a fine short story.

\section{Instructing Creative Reading and Writing (Short Story):}

As Creative reading and writing is a very wide range of literature, consequently, different teachers as well as colleges have their own way of presenting it. It is obvious that creative reading and writing instruction is one of the few areas in Libyan schools and universities that were given preferential treatment. The courses that are provided are not professional 
in preparation. There is a lack of influence and interest among Libyan students, because of the ways Libyan teachers teach. Morley (2007) says that a major skill of writing is to create a context in which other people can think. Some teachers prefer to focus on flash forwards/backwards. Millward (1998) in Galton (1988) believes that time expressions such as after two years, three months ago couldkill the readers' interest and make them feel bored as if they have gone to the time shift. Furthermore, Millward claims that it will not be "confusing for the readers to read the flashback and readers should smoothly accept the flashback without having to mention it precisely" (p.72).In addition, Small (2014) believes "It is very important in a short story class to ask the students in the classroom to write a story from imagination or after watching a video or looking at some pictures and photos "(p.32). For example, creative reading and writing in Libya is not taught as the name implies, it is taught by focusing on students ability, to be more clear on the talents they have, not on the skills they may acquire to be creative.

In creative writing, all adverbs must die so we concentrate on the importance of giving the power to the verb. For instance, the sentence $I$ ran quickly becomes I sprinted. I shouted loudly becomes I screamed. Once students realize the potential in this, they quickly kill adverbs and load the power of the action onto the verb.Ziegler (2002), mentioned that another teacher from State Oregon University has different opinions. "I ask students to spend one minute writing a sentence of narrative, any length, any tone, anything. Then, I say, spend one minute writing another sentence of narrative that in no way relates to the first. When they are done, I say, now, connect them with one of the following, Consequently, 
In spite of that, But, And then, Amazingly or Of course"(p. 41). This way, not only the students will come up with something creative but also they will be motivated by their teachers in a totally new and simple way. This step by step writing can be very helpful for the students' benefit. In addition, creative writing has many styles in teaching; teachers have different tastes, approaches, methods and techniques. For example, one way to apply on students is to teach them to be creative by providing a framework, which is like a skeleton and ask students to fulfill it with their creativity, which is the flesh. The poet Cowper in Small (2014) once penned " variety is the very spice of life, that gives it all its' flavor"(p.2). Libyan EFL teachers should understand that in order to teach creative writing successfully they have to think of ways, ideas, suggestions, methods, and techniques that interests and motivates students. For example," it is very important to ask students from the very first class to write up a story from the picture"(Small, 2014, p.32). Creative writing teachers should show, not tell, display a selection of sentences then tell the students something and then ask them to rewrite it in a way that presents the same information, such as paraphrasing creatively. For example," the man was angry could become; the man clenched his fists and hissed beneath his breath. It is about unpacking the emotions and finding ways to let the reader see the story for themselves" (Small, 2014, p.33). From the above, it is clear that teachers should concentrate on showing students how, not on the talents and skills they already have.

\section{Motivating Students:}

Libyan EFL teachers continue to believe that teaching creative reading and writing is mainly a matter of direct instructions; they cannot 
escape the recognition that there is much more to teaching than that. Ayers (1993) states that teaching should not be all about lecturing, because if so, the teacher may become only a distant guide and then an evaluator to certify competence (p.128). In addition, to provide more support "no matter how much reading, writing, observing the student undertakes, the only way to develop these skills fully is by using them in actual interpersonal situation" (Ments, 1983, p.24). Which means "effective learning involves practical experience" (Yaxley, 1990, p.93).Libyan EFL Teachers need to be totally aware of the ways students use and follow to inspire themselves. They need to be aware of individual differences among students. The ones that are already talented and skillful and also the others who try hard to be creative in reading and writing but most of the time are not successful. Almost all creative writers are individual in proving their work, each one is different from the other in terms of writing styles. Once Libyan EFL teachers vividly recognize the tremendous variation among learners - motivation, styles, and strategies- they will be in a position to work towards establishing a classroom community filled with independent, confident and active learners in creative reading and writing. Giving students choice assignments can boost creativity and motivation. "Effective teaching of creative writing involves the development of selfmotivation by providing enjoyable, interesting and purposeful activities" (Yaxley, 1990, p. 92). On the contrary, requesting creative responses often cause the exact opposite of creativity. I am not creative; this response can be expected from the students inside the classroom when asked to write something creative, as a result of this kind of response, Libyan EFL teachers has to be able to face this situation. In this case, students should 
be motivated by raising their self-confidence, once students are taken in hands, their creativity will come up itself. The significance of the classroom environment for not only its effects on the processes of learning and motivation, but also on self-esteem, emotional adjustment, and social being"(Ames\&Ames, 1984, p.15).To illustrate this, learners may select one of these possible projects:

- Classroom debate: Four to six students: This is when two groups of students have a debate or an argument about some literary work and as a result, something creative comes out.

- Website analysis and Web page construction: One per student: This can be an individual work as the students are asked to analyze a specific website into his/her own words using different expressions and creativity.

Hornby (2000) says "Never waste a journey. They can be a fertile breeding ground for ideas. If you are not fascinated by what is going around you, and you cannot get a story out of the gossiping couple opposite, then look out of the window"(p.22). He adds to this more questions to help raise creativity "What season is it? What is the weather like? Is the train/car/cycle swaying, going fast, slow, why? By now you should be teeming with ideas" (pp. 22-23).The key is to have a sufficient atmosphere for creativity as we all know creativity follows interests. If you are interested in the topic, you would flow in your writing. When teachers' skills in motivating learners are recognized as central to teaching effectiveness (Thanasoulas, 2002, p.3), Libyan EFL teachers will benefit in theirown professional development and satisfaction by perceiving that 
"motivation is an important educational outcome worthy of study in its own right" (Ames\&Ames, 1984, p.xi).

\section{Steps to begin a story:}

To begin a story, there are many different techniques a writer might use. First and most important, is for the writer to do reading. Reading creatively and critically plays an essential role for writing. It helps grow students' knowledge on how to write creatively. Reading other peoples' creative writing can help lead many to follow other professional writers. Reading conceptualized as being a unidirectional process from the printed page into the mind of the reader. This means that reading is viewed as a process of building symbols into words, words into sentences, and sentences into overall meaning. Parry(1996) suggests that" reading consisted of piecing together graphemes to form word, words to form sentences, sentences to form paragraphs, and so on"( p.668). Furthermore, to show the importance of reading before writing Smith (1982) identifies reading as " a matter of making sense of written language rather than decoding print to sound, a theoretical position that has become known as'psycholinguistic"(p.2). Therefore, when the writer starts to write, the second step is to consider that the narrator has to select the most appropriate method to follow. Moree (1968) says "Ask yourself such questions as these: do I want my story to open with the sound of voices as people discuss something about their lives?" (p. 34). In fact, other writers mention two essential procedures which insist on bringing one important character forward into the descriptive spotlight and let the readers have a good, long look at that character before actions begin. Galton (1988) mentions " You become a good writer just as you become a good 
carpenter: by planning down your sentences."(p.223). So, the third step is Planning, it is a sufficient step before writing which depends first on the writer's background about the required topic. As Goodman (1967) believes that reading should be planned because itdoes not involve just information from the text; it also involves the knowledge that the reader brings to the text in order to write creatively at the end (p. 127)

Finally, this last step is also very important, which is to have students watch video clips of famous writers talking about their experience and pain they have gone through. And this could really help students to engage with their work and write creatively, because, they are exposed to an entertaining experience that leads to imitation and performance to the style of the experienced writers. What is needed is more reflection on how to use these steps and which is more appropriate and which should be ignored, in a manner that meets the needs of students and ensures full satisfaction. This means, it is very important for teachers to help students when beginning to write a story to put their effective filter down in order for students to feel confident, confortable, relaxed and pleasant before writing a story.

\section{Methodology:}

\section{Research Design:}

The research design is an overview of the methodology section which presents the methods used in the research paper. The research design that is used in this paper is not only qualitative but also quantitative. For the qualitative methods, it is used to answer how as in how the language problems made in the short story can be solved. As for the quantitative method, it is used to answer how many as in how many 
language problems do excellent, good and weak students face in creative writing and short story. In brief, both statistical and non-statistical methods are used.The descriptive method of research was used in this study. A descriptive study determines and reports the way things are. It can only measure what already exists. The current study took on such a method to present a short story as an instrument in conducting critical analysis of writing.

\section{Participants:}

The participants chosen for this research paper were twelve undergraduate students from the Faculty of Arts, English department, Misurata University, Libya. The subjects were selected none randomly based on their level in writing, that is their marks in the subject short story. For example, the marks should not be less than 85 for the excellent students, 65 for the good students and 50 for the weak ones. The sample was selected from the total population of approximately 160 students. Also, two male and femaleteachers, interested in writing, volunteered themselves for this paper and were interviewed. See questions in appendix A, part: 5 .

\section{Research instrument:}

A mixed instrument of questionnaire was used, writing test, and a 5-point likert scale and 4 teachers were passed questions for an interview. Participants were giving only one day to fulfill the required questionnaire about the problems they face in the two mentioned subjects, See appendix A. The questionnaire is divided into two parts. Part one, is the questions to find out the main problems, and part two is for the participants to write a passage by showing rather than telling. Also, the aim is to evaluate the 
problems participants encounter in writing a short story in grammar, first language, interference, punctuation, vocabulary choice and prepositions. The participants were informed prior to the questionnaire and the writing test that no marks will be shown in the research or the personal information will be presented. They were informed that the purpose of contributing to this study is totally academic and confidential.

\section{Procedure:}

The participants were given a letter of consent prior to the questionnaire and the writing test. It is to give them the instructions and the condition of being totally honest in the feedback and they were free to back out before starting to answer.Prior conducting this study, a sample questionnaire was given to three random students to receive a feedback in order to find out if some improvement and modification is required, and some were made. For example, there were 10 point likert scale and 10 passages to write in order to analyze, the feedback was negative, stating that the 10 passages were too much for them to write and 10 likert scale can be confusing, both of the questions were changed from 10 to 5.After collecting the data needed for the paper, the analysis process took place, see appendix A-B.

\section{Data analysis:}

Pie charts to illustrate the data were used and that was to present the data in an organized way. All the data was collected and divided into three different groups, excellent, good and weak. The aim was to compare between the different groups of students, that is, not only to see what types of mistakes they made but also that which level of students made more mistakes and in which field.After that, the three above mentioned groups were further divided to analyze the language problems. For 
example, despite of being excellent in short story, the students encountered more vocabulary problems compared to the good ones. Furthermore, the good ones were more superior in grammar then the weak ones and the weak subjects were weak in all. Then pie charts were divided into two parts, first to provide the pie charts with the percentage based on the subjects answers in the 5-point likert scale and in the second part was to present the pie charts but after analyzing their answers in the writing test. The percentages in both pie charts were very much different.

\section{Results and Discussions:}

The aim of presenting the results is to show the readers, especially teachers, different types of language problems the students face in creative writing/ short story, and to what extent. Below are 10 pie charts presented, each one divided into three colors where the blue color presents the excellent students, the red color is the good and the green is the weak ones. According to the Likert scale (Before analysis)

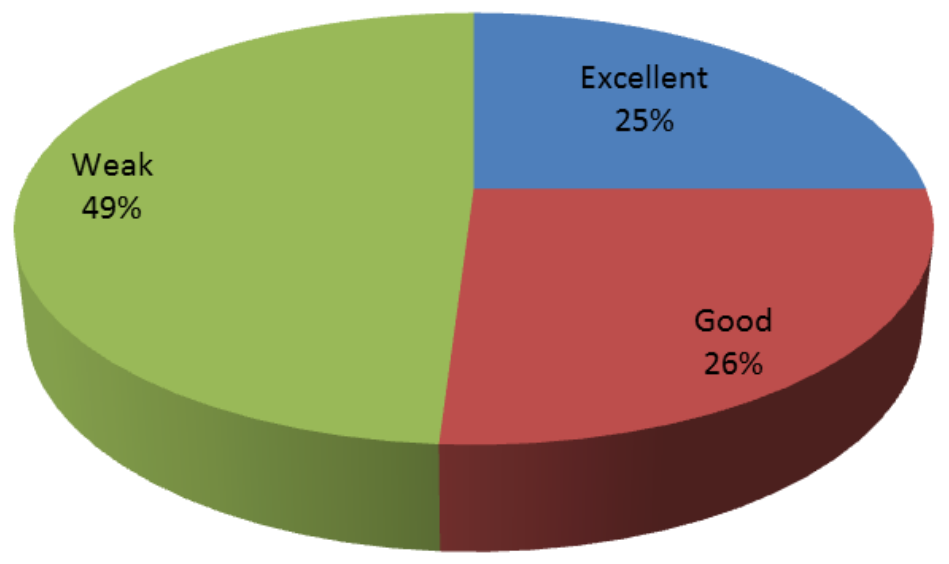

Figure 1 (Grammar)

As seen in figure 1 , when the participants were asked the questions 
provided with the 5 point Likert scale, the above given percentages were their answer, where almost half of the sampling, 49\%, are the weak ones in grammar difficulties and $26 \%$, the good students and rest of the $25 \%$ are the excellent.

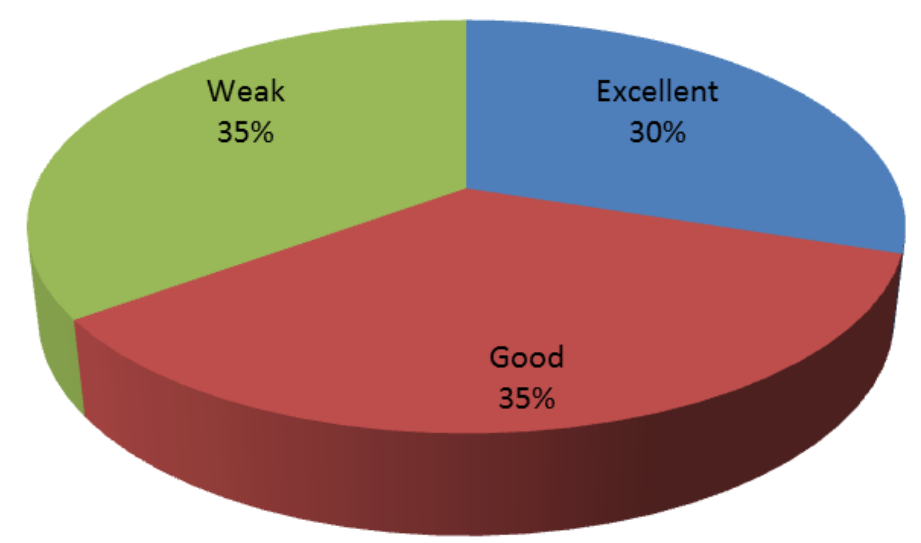

Figure 2 (Vocabulary)

This chart presents the problems that the subjects face or they think they face in vocabulary. The weak and the good ones gave the same answer as their total percentage was $35 \%$ difficulties in vocabulary and the excellent ones face $30 \%$. 


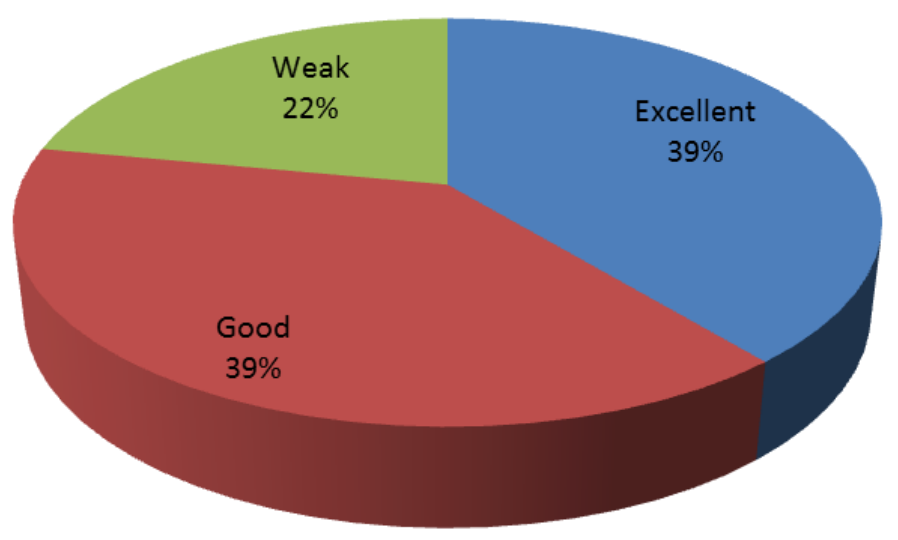

Figure 3 (Preposition)

In this chart, the prepositional problems are evaluated, and strangely, the good and the excellent students, both $39 \%$, seem to encounter more difficulties than the weak students who are only $22 \%$.

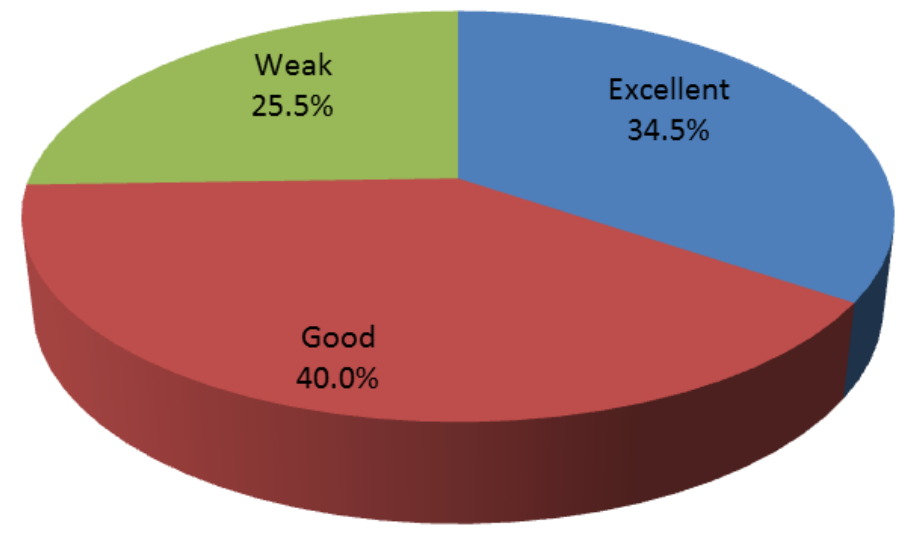

Figure 4 (Punctuation)

Even in this figure, the punctuation problems, the weak students tend to face the lowest problem, $25.5 \%$ compared to good, $40 \%$ and the excellent students, $34.5 \%$. 


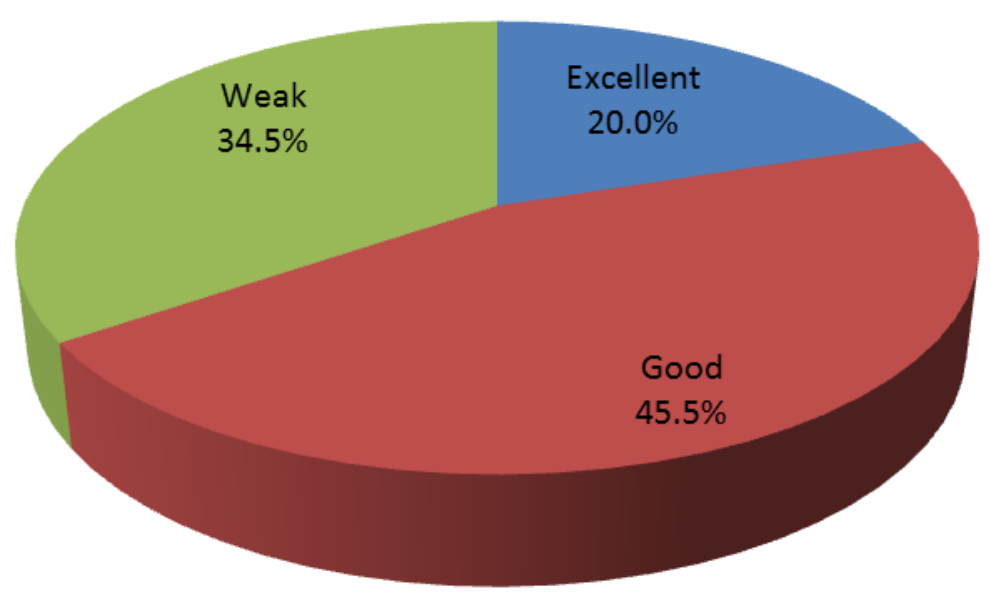

Figure 5 (Language Interference)

The excellent students believe that they do not interfere their first language more often in their writing, only $20 \%$, although good students are $45,5 \%$ and the weak students, better than the good ones in this area, $34.5 \%$.

\section{After Analysis:}

The above five figure presented the percentages based on the students' answers but after their writing test, was corrected and their mistakes were compared, the following actual percentage came up as a result. 


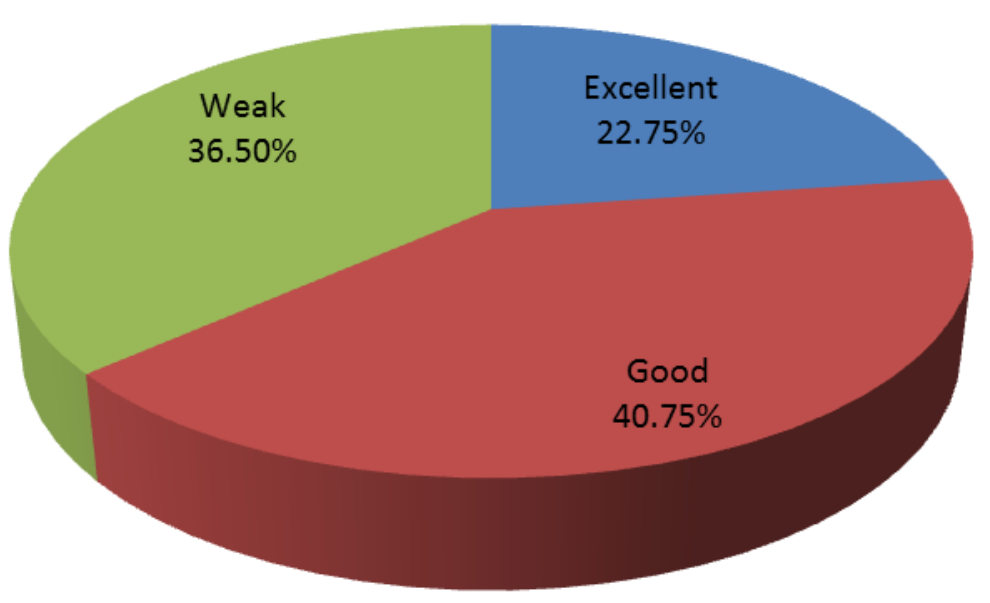

\section{Figure 6 (Grammar)}

After analyzing the writing test, it has been seen that students have misconceptions about their level in writing, whereas the weak students believed that they have the highest number of grammar issues, it is seen that the good students are the first in grammatical errors, 40.75\%, although the weak students got lower marks than them in the subject SS, they are still better in grammar, $36.50 \%$ and the excellent ones have the lowest number of grammar errors, $22.75 \%$. 


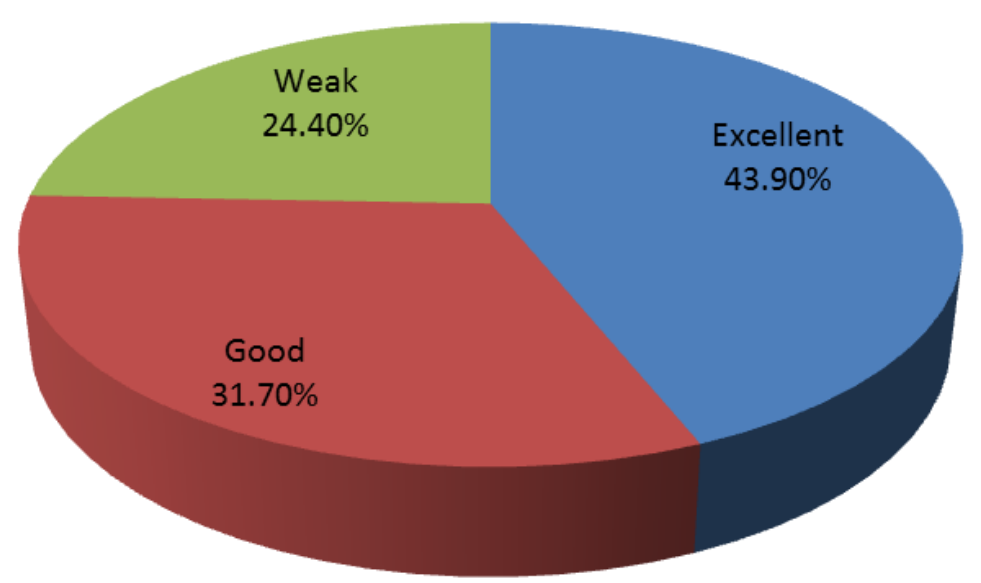

Figure 2 (Vocabulary)

Surprisingly, the excellent students were the ones who faced the highest number of vocabulary problems, $43.90 \%$ that is to choose unsuitable words, and they are not aware of their weakness in vocabulary, because when they were asked they said it to be only 30\%. The good students, $31.70 \%$ and the weak ones $24.40 \%$ are better in vocabulary than the excellent where the weak students face the least problems 


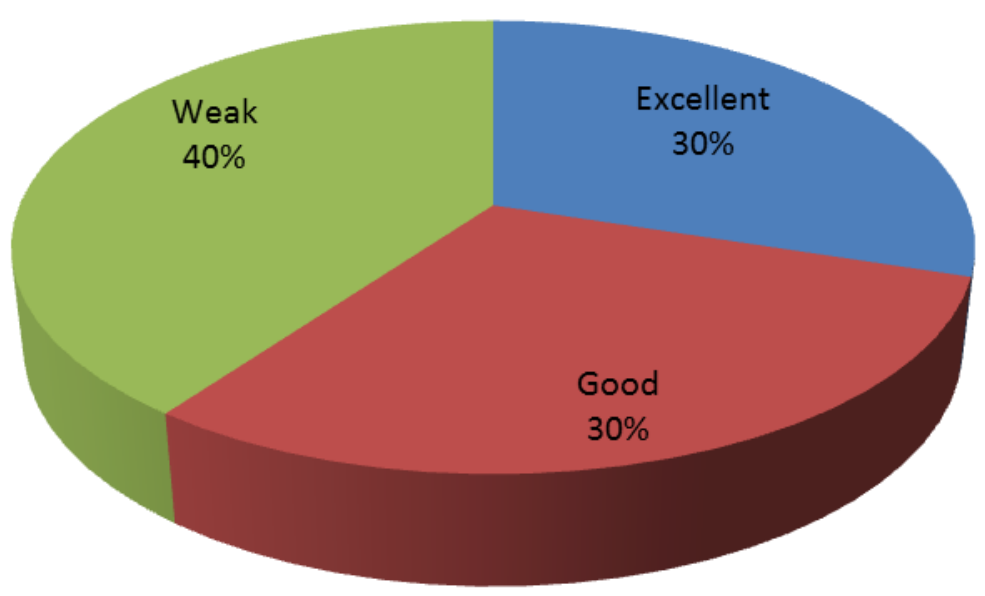

The same thing again where the excellent students actually are not aware of using the appropriate preposition with the right adjective, two common examples are, angry from, absent from, they face the same number of problems like the good ones, $30 \%$ where the weak students are $40 \%$.

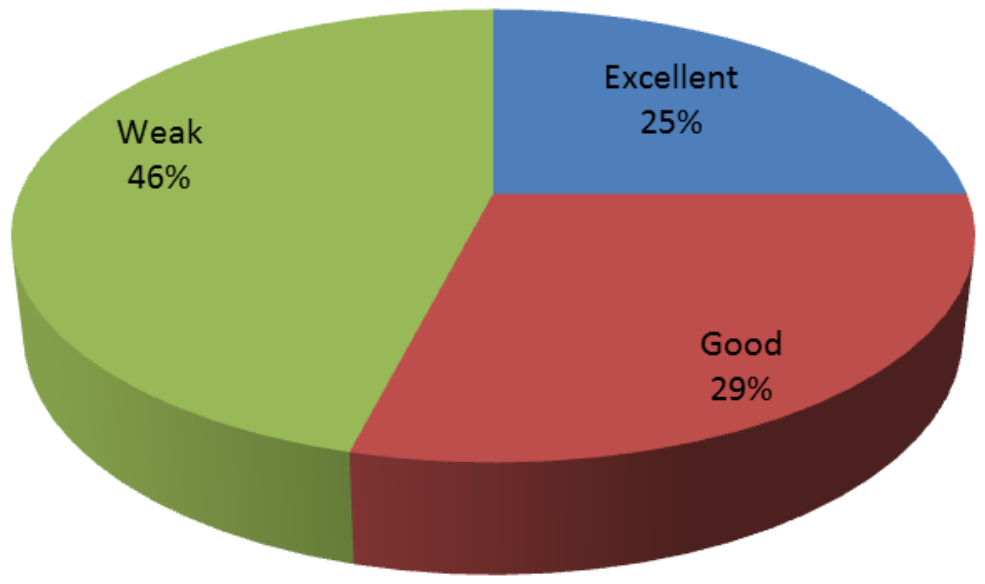

Figure 4 (Punctuation) 
The use of punctuation is very important in writing, and it seems as if this is what makes the weak students, weak! They faced $46 \%$ of punctuation problems with no full stops, no commas, not differentiating between semi colon and exclamation marks, the good ones $29 \%$ and excellent even lower, $25 \%$.

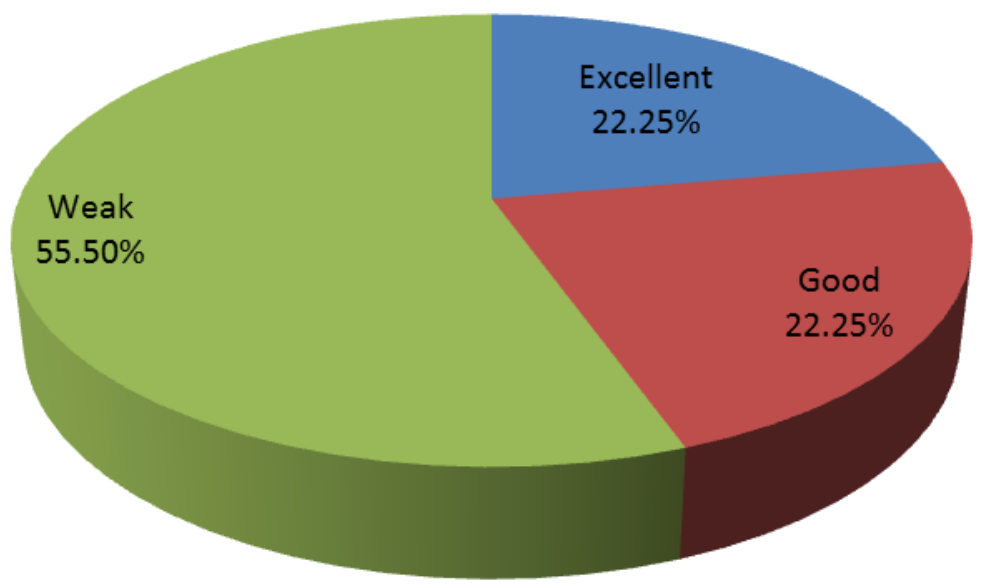

Figure 5 (Language Interference)

The weak students think in their first language before writing and that affects their writing very much, $55.50 \%$ of the weak students interfere their first language in writing; however as for the excellent and good students, only $22.25 \%$ of the students face this problem.

To sum up, it is seen that what students believe is not always the truth, they evaluate themselves based on their final marks in SS, but the actual assessment of SS is mostly not correct, if it was the above result would not be like this! The result where excellent students in vocabulary face more difficulties than the good and weak ones, and what is writing without vocabulary? It is nothing, so how did these students get excellent? 
It depends on how the exams are designed, mostly based on memorization, favoritism and evaluation by name.

\section{Conclusion:}

Creative writing is not an easy course to teach yet it is an interesting task to learn especially in considering Short Story. Writing can change people and create new worlds parallel to actual offering examples of life and nothing less. The fact is that teachers should be aware of all the procedures and techniques of motivating their students in learning how to write. In addition, teachers should realize that creative writing is a talent or a skill that has to be practiced; therefore, they should find a way to help students grow their ability in being creative. It is clear that there was a significant relationship between what the learner writes and what he/she reads which is called creative reading.in order for students to write creatively, they should read to grow their ability in vocabulary, grammar, organization, structure, imagination, punctuations, and different type of writings...etc. As Parry (1996) believes that reading someone's piece of work is an essential step for developing the skill of writing and that provides the history or background about the expected text even an imagination for an inspired story (pp.665- 668). It can be concluded that the more the learner reads, the more he/she writes and creates.

\section{Recommendations:}

Based on the findings and conclusions extracted from this study, the following are recommended:

1. Since a high percentage of students have difficulties in grammar and vocabulary, teachers should advise their students on reading regularly. 
2. Colleges may provide more facilities or programs for creative writing. A journey to see the wonders of nature is a pleasant idea to think about.

3. Teachers need to be aware of the activities inside the class as the course of creative writing needs practice and experience based on the extent of the learner's imagination and creativity.

4. Timed classroom activities could be one way to pressure them to build their skills in Creative Writing. Music can be attached to such an activity to create writing mood.

5. Conducting any creative piece of work requires a comfortable, peaceful, relaxed and a quite environment. 


\section{Appendices}

\section{Appendix A:}

Creative Writing: Language Problems Undergraduate Students face in Short Story

Introduction:

Thank you in advance for accepting our questionnaire. Answering it will help us in a great deal to find out facts concerning our research which we are conducting this semester for out graduation project.

We would be very grateful if you provide us with an honest feedback by answering each question.

If you could please fill out the following background information.

Note: No marks for the writing test, it is only for academic purpose.

Put a circle on the correct answer.

Part 1: General Feedback
A. Your age:
$\begin{array}{lll}\text { 1. } 18-20 & 2.21-25 & 3.26-30\end{array}$
B. Your gender:
1. Male 2. Female
C. Have you ever been abroad before?
$\begin{array}{ll}\text { 1. Yes 2. No } & 0\end{array}$
D. Your level as a writer in your opinion:
1. Excellent 2. Good 3. Poor
E. In which semester are you?
$\begin{array}{lllll}1.4 & 2.5 & 3.6 & 4.7 & 5.8\end{array}$
F. Your name (Optional)

G. Date 
Part 2: Educational Knowledge

1. Do you think reading is essential before writing?
a) Yes
b) No

Comments

2. Do you think non-academic people can be successful in creative writing?
a) Yes
b) No

Comments

3. Have you ever written a piece of writing or a short story? If yes, what was it?
a) Yes
b) $\mathrm{No}$

Comments

4. Do you face any difficulties in writing? If yes, what are they?
a) Yes
b) $\mathrm{No}$

Comments

5. Do you think writing techniques helps in creative writing?

a) Yes

b) No

\section{Comments}

Part 3: Evaluation Sample Questionnaire

Note: 1 being the lowest difficulties and 5 being the highest.

\begin{tabular}{|l|l|l|l|l|l|}
\hline & 1 & 2 & 3 & 4 & 5 \\
\hline $\begin{array}{l}\text { How confident do you feel as } \\
\text { a writer? }\end{array}$ & & & & & \\
\hline $\begin{array}{l}\text { To what extent do you face } \\
\text { difficulties in vocabulary? }\end{array}$ & & & & & \\
\hline
\end{tabular}




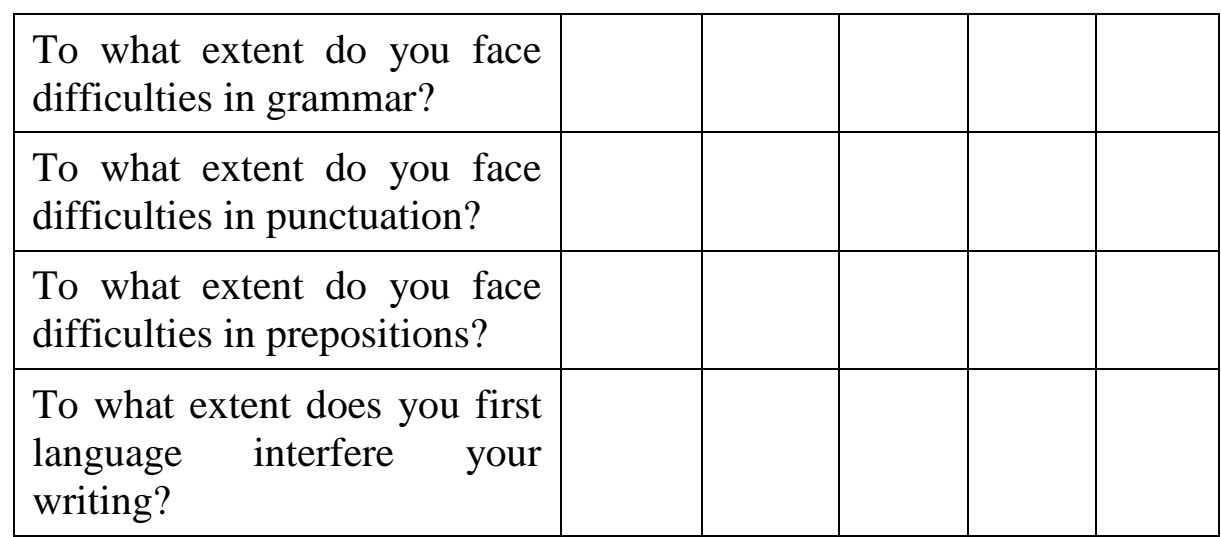

Part 4: Creative Writing Test

Instructions: Write a passage that "shows" rather than "tells" for each of the sentences below.

1. The streets in December are crowded.

2. My college is on a very busy street. 
3. She lived sadly after her husband died.

4. I have a fun hobby.

5. My graduation party is going to be the best ever.

6. He/she is my best friend. 
Thank you for your time.

Part 5: Four teachers also volunteered in this research paper by sharing their ideas, and they were asked the following questions on which they commented on:

1. How creative the teacher him/herself has to be for the students to be creative writers?

2. Which teaching method is most suitable when it comes to improve creativity in the students' writing?

3. How would you as a teacher take best care of language problems (vocabulary, grammar, punctuation, preposition, and language interference) along with the creativity in students' writing?

4. What are the facilities missing in the Faculty of Arts that is becoming the obstacle in tackling the issue of creative writing?

\section{Appendix B:}

The students' grades in the subject Short Story.

Excellent students:

1. 97

2.93 
3.86

4.80

Good students:

1.71

2.77

3.72

4.70

Weak students:

1.53

2.59

3.60

4.63 


\section{References}

Ames, R. \& Ames, G. (1984). Research on Motivation in Education: to Classroom Milieu. Academic Press, Inc, Harcourt Brace Jovanovich Publisher.

Ayers, W. (1993). To Teach: The Journey of a Teacher. New York Teacher College Press.

Galton, D. (1988). How to Write and Sell Short Stories: The Old School. UK.

Goodman, K. S. (1967). 'Psycholinguistic Universals in the Reading Process'. In P. Pimsleur and T. Quinn (Eds.). The Psychology of Second Language Learning. (135-142). Cambridge: Cambridge University Press.

Hornby, A. S. (2000). Oxford Advanced Learner's Dictionary of Current English: Seventh Edition. Oxford University Press.

Mcgurl, A. (1998). How to Write and Sell Short Stories. Oxford University Press.

Ments, M. V. (1983). The Effective Use of Role Play: A Handbook for Teachers and Trainers. Worcester, Great Britain: Sons Limited.

Moree. E. (1968). Picking and Choosing. Canada:York University Press.

Morley, D. (2007). Creative Writing. New York: Cambridge University Press.

Mullik, B. R. (1980). A Critical History of English Literature. First Edition. Lahore: Ali Co.

Parry, K. (1996). Culture, Literacy, and L2 Reading. TESOL Quarterly, 30 (4). 665-693. 
Small. S. (2014). Different Styles in Teaching Creative Writing. ESL Magazine. Pdf. Retrieved from http://sarahsmall.com/.

Smith, F. (1982). Understanding Reading. $3^{\text {rd }}$ Ed. New York: Holt, Rinehart and Winston.

Stinger. H. (2002). On Teaching and Writing Fiction. Retrieved from http://www.teachingideas.co.uk/english/contents_writingfiction.htm. Thanasoulas, D. (2002). Motivation and Motivating in EFL. Motivation and Motivating in The Foreign Language Classroom. http://teachers. Englishdub.com/artide/motivation- and motivating in EFL.htm.

Yaxley, B. G. (1990). Developing Teachers' Theories of Teaching. A Touchstone London. New York. Approach: The Falmer Press.

Ziegler. A. (2002). Creative Writing Workshop. Columbia University: Retrieved from http://gs.columbia.edu/major-title?majorid=1811. 